\title{
Identification of Novel and Potent Indole-Based Benzenesulfonamides as Selective Human Carbonic Anhydrase II Inhibitors: Design, Synthesis, In Vitro, and In Silico Studies
}

\author{
Ahmed Elkamhawy ${ }^{1,2} \mathbb{D}^{D}$, Jiyu Woo ${ }^{1}$, Hossam Nada 1,3 ${ }^{\mathbb{D}}$, Andrea Angeli ${ }^{4}\left(\mathbb{D}\right.$, Tarek M. Bedair ${ }^{5}$, \\ Claudiu T. Supuran $4, *$ (D) and Kyeong Lee ${ }^{1, *}$
}

check for

updates

Citation: Elkamhawy, A.; Woo, J.;

Nada, H.; Angeli, A.; Bedair, T.M.;

Supuran, C.T.; Lee, K. Identification of Novel and Potent Indole-Based Benzenesulfonamides as Selective Human Carbonic Anhydrase II Inhibitors: Design, Synthesis, In Vitro, and In Silico Studies. Int. J. Mol. Sci. 2022, 23, 2540. https://doi.org/ $10.3390 /$ ijms 23052540

Academic Editor: Joan Roselló-Catafau

Received: 26 January 2022

Accepted: 24 February 2022

Published: 25 February 2022

Publisher's Note: MDPI stays neutral with regard to jurisdictional claims in published maps and institutional affiliations.

Copyright: (C) 2022 by the authors. Licensee MDPI, Basel, Switzerland. This article is an open access article distributed under the terms and conditions of the Creative Commons Attribution (CC BY) license (https:// creativecommons.org/licenses/by/ $4.0 /)$.
1 BK21 FOUR Team and Integrated Research Institute for Drug Development, College of Pharmacy, Dongguk University-Seoul, Goyang 10326, Korea; a_elkamhawy@mans.edu.eg (A.E.); wju2757@dgu.ac.kr (J.W.); hossam_hammouda@dgu.ac.kr (H.N.)

2 Department of Pharmaceutical Organic Chemistry, Faculty of Pharmacy, Mansoura University, Mansoura 35516, Egypt

3 Pharmaceutical Chemistry Department, Faculty of Pharmacy, Badr University, Cairo 11829, Egypt

4 NEUROFARBA Department, Sezione di Scienze Farmaceutiche, University of Florence, Via Ugo Schiff 6 , Sesto Fiorentino, 50019 Florence, Italy; andrea.angeli@unifi.it

5 Chemistry Department, Faculty of Science, Minia University, Minia 61519, Egypt; dr.tarek.bedair.2@gmail.com * Correspondence: claudiu.supuran@unifi.it (C.T.S.); kaylee@dongguk.edu (K.L.)

\begin{abstract}
In recent decades, human carbonic anhydrase inhibitors (hCAIs) have emerged as an important therapeutic class with various applications including antiglaucoma, anticonvulsants, and anticancer agents. Herein, a novel series of indole-based benzenesulfonamides were designed, synthesized, and biologically evaluated as potential hCAIs. A regioisomerism of the sulfonamide moiety was carried out to afford a total of fifteen indole-based benzenesulfonamides possessing different amide linkers that enable the ligands to be flexible and develop potential H-bond interaction(s) with the target protein. The activity of the synthesized compounds was evaluated against four hCA isoforms (I, II, IX and, XII). Compounds $\mathbf{2 b}, \mathbf{2 c}, \mathbf{2 d}, \mathbf{2 f}, \mathbf{2 h}$ and $\mathbf{2 o}$ exhibited potent and selective profiles over the hCA II isoform with $\mathrm{K}_{\mathrm{i}}$ values of 7.3, 9.0, 7.1, 16.0, 8.6 and $7.5 \mathrm{nM}$, respectively. Among all, compound 2a demonstrated the most potent inhibition against the hCA II isoform with an inhibitory constant $\left(\mathrm{K}_{\mathrm{i}}\right)$ of $5.9 \mathrm{nM}$, with 13-, 34-, and 9-fold selectivity for hCA II over I, IX and XII isoforms, respectively. Structure-activity relationship data attained for various substitutions were rationalized. Furthermore, a molecular docking study gave insights into both inhibitory activity and selectivity of the target compounds. Accordingly, this report presents a successful scaffold hoping approach that reveals compound $\mathbf{2 a}$ as a highly potent and selective indole-based hCA II inhibitor worthy of further investigation.
\end{abstract}

Keywords: indole based-benzenesulfonamide; amide coupling; carbonic anhydrase inhibitors; molecular docking; structure-activity relationship (SAR)

\section{Introduction}

Carbonic anhydrases (CAs) are metalloenzymes found in all living things that are required for the conversion of $\mathrm{CO}_{2}$ to bicarbonate and protons [1]. CAs observed in humans belong to the $\alpha$-class ( $\alpha$-CA), and are classified into sixteen isoforms that vary in molecular characteristics, oligomeric structure, cellular localization, distribution in organs and tissues, expression levels, and kinetic properties [2]. The distribution pattern of the CA isoforms can be described as, cytosolic (I, II, III, VII, and XIII), membrane (IV, IX, XII, and XIV), secretory (VI), and mitochondrial (VA and VB) forms [3,4]. Carbonic anhydrases have a role in a variety of physiological processes, including respiration, $\mathrm{pH}$ control, ion transport, bone resorption, and gastric fluid secretion. As a result, inhibitors of these enzymes have become an important therapeutic class in recent decades. Topically acting antiglaucoma, 
anticonvulsants, and anticancer agents are some of the novel applications of CA inhibitors that have been developed [2,5]. Among the CA isoforms, CA II is widely associated with various types of cancers, with a recent study finding that it is expressed in the endothelium of neovessels in melanoma, esophageal, renal, and lung cancers [6]. Other studies associate CA II with the key target antigen stimulation of an autoantibody response in melanoma patients [7]. The most common approach in designing selective CA inhibitors has been through the modulation of the ring directly linked to the zinc-binding group (ZBG) or by appending different tails to the aromatic ring [8,9].

One of the most prominent ZBG moieties with carbonic anhydrase inhibitory activity are sulfonamides [10]. Among the investigated sulfonamides, aromatic sulfonamides have been shown to be specific and potent inhibitors of CA isoforms, and they have been considered as potential candidates for the further development and enhancement of more potent inhibitors [11]. Conversely, due to the structural similarity and identical subcellular location of the CA isoforms, carbonic anhydrase inhibitors suffer from a lack of selectivity which often results in unwanted side effects [12]. When designing inhibitors for the metalloenzymes carbonic anhydrases, sulfonamides are regarded as one of the most effective ZBGs among the studied sulfonamides. This is due to their structural features that are ideal for binding to the $\mathrm{Zn}^{2+}$ ion in the active site of the receptor [13-15]. The negatively charged nitrogen of sulfonamide coordinates the positively charged metal ion $[9,16]$. Accordingly, the primary sulfonamide group $\left(\mathrm{SO}_{2} \mathrm{NH}_{2}\right)$ plays an important role in CA inhibition mechanism, with more than 20 compounds in clinical use including acetazolamide (AAZ) I, methazolamide II, and ethoxzolamide III (Figure 1).<smiles>CC(=O)Nc1nnc(S(N)(=O)=O)s1</smiles>

Acetazolamide (AAZ) I<smiles>CC(=O)N=c1sc(S(N)(=O)=O)nn1C</smiles>

Methazolamide II<smiles>CCOc1ccc2nc(S(N)(=O)=O)sc2c1</smiles>

Ethoxzolamide III

Figure 1. Chemical structures of some clinically used sulfonamide-containing drugs.

The indole scaffold has been identified to afford highly potent carbonic anhydrase inhibitors. A recent series of indole-1,2,3-triazole chalcone hybrids was synthesized by click chemistry as CA inhibitors (general structure IV, Figure 2). Although some compounds of this series were able to successfully inhibit the cytosolic isoform hCA I in a low nanomolar range of potency $(18.8-50.4 \mathrm{nM})$, they did not show a similar potency over the tumorassociated hCA II isoform. The tumor associated isoform hCA IX was also weakly inhibited by all the synthesized compounds with $\mathrm{K}_{\mathrm{i}}$ values ranging from $69.3 \mathrm{nM}$ to $1.4 \mu \mathrm{M}$ [17]. Another series of sulfonamidoindole-based hydrazones possessing a 2-(hydrazinocarbonyl)3-phenyl-1H-indole-5-sulfonamide scaffold (general structure V, Figure 2) was reported with CA inhibitory activity for the tumor-associated carbonic anhydrase isoforms, hCA IX and XII. Despite the high potency of these derivatives against hCA IX and XII, they displayed weak inhibitory activity against both hCA I isoform $\left(\mathrm{K}_{\mathrm{i}} \mathrm{s}\right.$ range: from $3.13 \mu \mathrm{M}$ to $>10.00 \mu \mathrm{M})$ and hCA II isoform $\left(\mathrm{K}_{\mathrm{i}} \mathrm{s}\right.$ range: from $309 \mathrm{nM}$ to $\left.>10.00 \mu \mathrm{M}\right)$ [18]. Peerzeeda et al. reported a series of sulfonamide derivatives of pyridyl-indole-based chalcone (general structure VI, Figure 2) as hCA IX inhibitors with antitumor activities against MCF-7 andHepG-2 cell lines [19]. $N$-aroyl-2-oxindole benzenesulfonamide conjugates (general structure VII, Figure 2) were also reported by George et al. to preferentially inhibit the tumor-associated isoforms IX and XII [20]. The same research group reported another series of 2-oxindole benzenesulfonamide conjugates (general structure VIII, Figure 2), with many compounds showing promising activity and selectivity toward CAI, II and IX compared to AAZ (I) [20]. Novel 4/3-((4-oxo-5-(2-oxoindolin-3-ylidene)thiazolidin-2ylidene)amino)benzenesulfonamides (general structure IX, Figure 2) were also recently reported as CA inhibitors. Isoforms II and IX (tumor-associated) were found to be more susceptible to inhibition by this series, with $\mathrm{K}_{\mathrm{i}} \mathrm{s}$ in the range of 2.6-598.2 nM for hCA II, and 
of 16.1-321 nM for hCA IX. Regarding clinical trials, indisulam (X, Figure 2) is one of these indole-based benzenesulfonamide anticancer agents. It was in phase II clinical studies until recently, and it inhibits several CA isoforms, including the tumor-associated isoform IX [21]. Moreover, another example in clinical trials is SLC-0111 (XI), a benzenesulfonamide compound currently in phase I/II clinical trials for the treatment of advanced metastatic solid tumors [22].

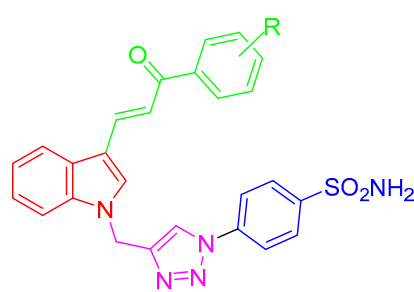

IV<smiles>[R]c1ccc(C(=O)N2C(=O)/C(=N\Nc3ccc(S(N)(=O)=O)cc3)c3ccccc32)cc1</smiles>

VII

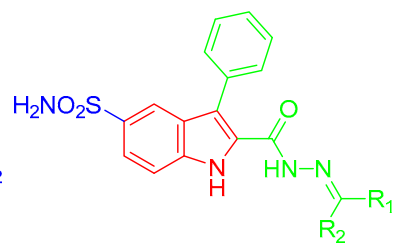

v

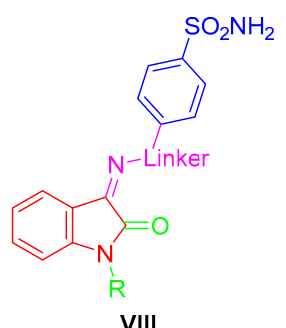

$\sqrt{1}$
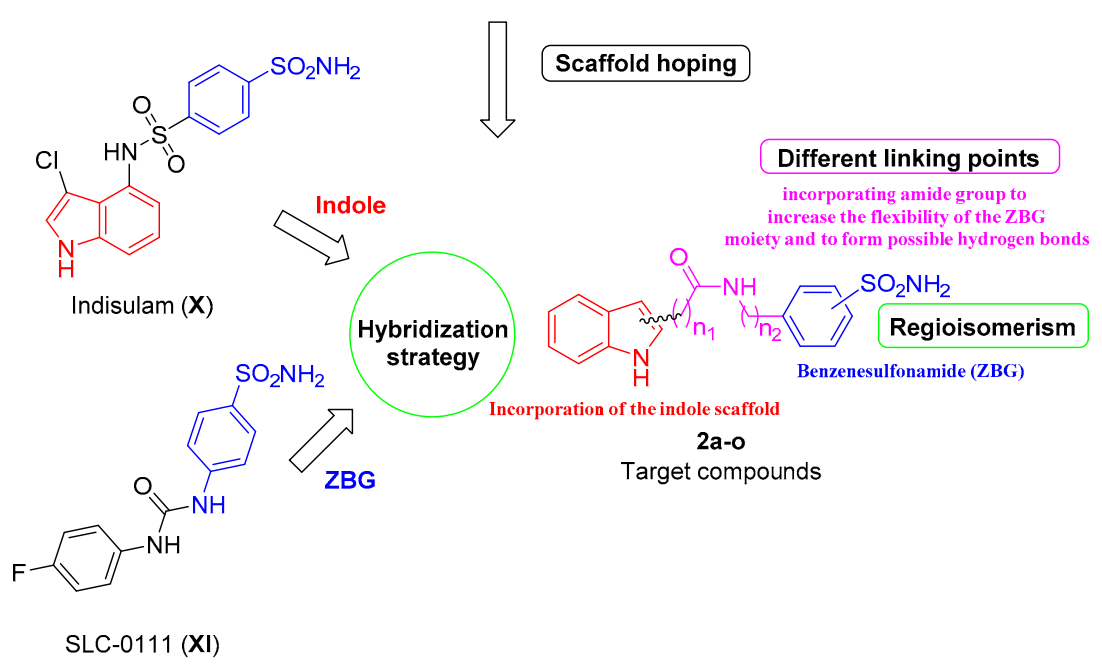

SLC-0111 (XI)

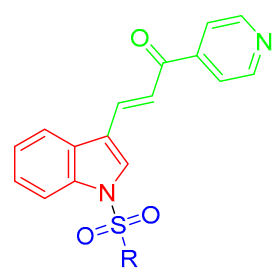

VI

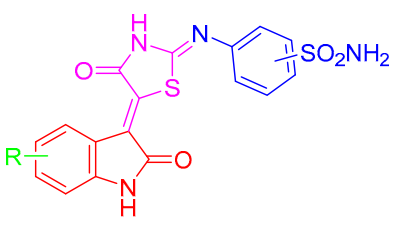

IX

Figure 2. Design strategy of the synthesized hybrids 2a-o.

Inspired by all these efforts related to the development of indole-based hCA inhibitors, we designed a novel series of indole-based benzenesulfonamides (Figure 2) through a hybridization process of these two scaffolds (indole and benzenesulfonamide). Thereafter, a regioisomerism of the ZBG moiety was carried out to afford fifteen indole-based benzenesulfonamides linked together via an amide linker, giving the synthesized compounds flexibility as well as the ability to form hydrogen bond interactions with the target protein. To the best of our knowledge, this hybridization approach of the indole moiety with the most effective ZBG moiety (the benzenesulfonamide group) via a flexible amide linker on different positions on the indole core to develop novel small molecules with a promising potential to inhibit carbonic anhydrase isoforms has not been reported so far. 


\section{Results and Discussion}

\subsection{Chemical Synthesis}

As shown in Scheme 1, a series of fifteen benzenesulfonamide analogues (2a-o) were synthesized via a coupling reaction of amide synthesis. The reaction was carried out utilizing a range of commercially available appropriate indole-based starting materials; 3 (1H-indol-3-yl)propanoic acid (1a), $1 H$-indole-5-carboxylic acid (1b), $1 H$-indole-6-carboxylic acid (1c), or $1 \mathrm{H}$-indol-5-amine (1d). Using coupling catalysts such as EDCI, HOBt, or T3P, several benzenesulfonamide reagents were allowed to react overnight at room temperature with the starting materials $\mathbf{1 a - d}$ (as described in Table 1) in a suitable solvent such as MeCN, DMF/DCM (5/1), or THF. As a result, a wide range of indole-based benzenesulfonamide analogues (2a-o) with diverse substituents were afforded in acceptable yields (Table 1).

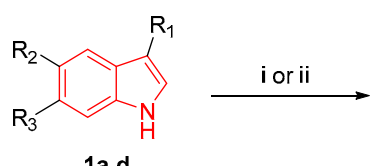

1a-d

1a: $\mathrm{R}_{1}=\mathrm{CH}_{2} \mathrm{CH}_{2} \mathrm{COOH}, \mathrm{R}_{2}=\mathrm{H}, \mathrm{R}_{3}=\mathrm{H}$

1b: $\mathrm{R}_{1}=\mathrm{H}, \mathrm{R}_{2}=\mathrm{COOH}, \mathrm{R}_{3}=\mathrm{H}$

1c: $\mathrm{R}_{1}=\mathrm{H}, \mathrm{R}_{2}=\mathrm{H}, \mathrm{R}_{3}=\mathrm{COOH}$

1d: $R_{1}=H, R_{2}=N_{2}, R_{3}=H$

Scheme 1. Reagent: appropriate benzenesulfonamide reagent (see Table 1). Conditions: (i) EDCI, HOBt, DIPEA, acetonitrile or DMF/DCM (5/1), rt, 12 h, or (ii) T3P, DIPEA, THF, rt, 12 h.

Table 1. Starting materials, reagents, and chemical structures of compounds $2 \mathbf{a}-\mathbf{o}$.

\begin{tabular}{|c|c|c|c|}
\hline Cpd & Starting & Benzenesulfonamide Reagent & Chemical Structure \\
\hline $2 \mathbf{a}$ & $1 \mathbf{a}$ & & \\
\hline $2 b$ & $1 \mathbf{a}$ & & \\
\hline $2 c$ & $1 a$ & & \\
\hline $2 d$ & $1 \mathbf{a}$ & $\mathrm{O}_{2} \mathrm{NH}_{2}$ & \\
\hline $2 e$ & $1 b$ & & \\
\hline $2 f$ & $1 b$ & $\mathrm{O}_{2} \mathrm{NH}_{2}$ & \\
\hline $2 \mathrm{~g}$ & $1 b$ & & \\
\hline $2 \mathrm{~h}$ & $1 \mathbf{b}$ & & \\
\hline $2 \mathbf{i}$ & $1 b$ & & \\
\hline $2 \mathrm{j}$ & 1c & & \\
\hline
\end{tabular}


Table 1. Cont.

\begin{tabular}{|c|c|c|c|}
\hline Cpd & Starting & Benzenesulfonamide Reagent & Chemical Structure \\
\hline $2 k$ & 1c & & \\
\hline 21 & 1c & & \\
\hline $2 \mathrm{~m}$ & 1c & & \\
\hline $2 n$ & 1c & & \\
\hline 20 & 1d & & \\
\hline
\end{tabular}

Different techniques were utilized to elucidate the chemical structures and the purity of the synthesized target compounds. The ${ }^{1} \mathrm{H}$ NMR spectra of compounds $\mathbf{2} \mathbf{a}-\mathbf{o}$ were characterized by the appearance of two peaks at 7.20-7.50 ppm attributable to the sulfonamide $\mathrm{NH}_{2}$ and another peak at 10.20-10.80 ppm attributable to the $\mathrm{NH}$ of the amide group confirming the formation of compounds $\mathbf{2 a}-\mathbf{o}$. Compound $\mathbf{2 a}$ synthesis was further confirmed by the appearance of two triplet peaks in the aliphatic region at 3.05-3.01 and 2.73-2.69 ppm attributable to the two $\mathrm{CH}_{2}$ groups of the aliphatic linker moiety. Similarly, compound $\mathbf{2 b}$ synthesis was easily confirmed by the appearance of the two triplet peaks attributable to the two $\mathrm{CH}_{2}$ groups, as well as a singlet peak at 10.77 ppm attributable to the $\mathrm{OH}$ substituent on the ZBG moiety. Compound $2 \mathrm{c}$ was characterized by the presence of four triplet peaks at 3.29-3.26, 2.90-2.88, 2.76-2.74 and 2.43-2.39 attributable to the four $\mathrm{CH}_{2}$ groups of the aliphatic linker moiety. In the same manner, the presence of triplet peaks in the aliphatic range of the ${ }^{1} \mathrm{H}$ NMR spectrum associated with the presence of $\mathrm{CH}_{2}$ groups in the linker moiety was used to confirm the synthesis of compounds $2 \mathbf{h}$ and $\mathbf{2 m}$.

\subsection{Carbonic Anhydrase Inhibition}

The CA inhibitory activities of the hybrid compounds $\mathbf{2 a - o}$ and AAZ, as a standard inhibitor, were measured against four isoforms of hCA by a stopped flow $\mathrm{CO}_{2}$ hydrase assay (Table 2). The tested CA panel was comprised of the two ubiquitously expressed cytosolic hCA I and II isoforms, along with the two tumor-related transmembrane hCA IX and XII isoforms. The activity of the synthesized hybrids was reported as $\mathrm{K}_{\mathrm{i}}$ (inhibition constant) to assess their binding affinity. Among the synthesized hybrids, compounds $\mathbf{2 a}$, $2 \mathbf{d}$ and $\mathbf{2 0}$ exhibited potent inhibitory activities against the hCA I isoform with inhibition constants $\left(\mathrm{K}_{\mathrm{i}}\right)$ of 79.8, 97.6 and $56.6 \mathrm{nM}$, respectively, compared to AAZ (250 nM). Compound 2a demonstrated the most potent inhibition among all compounds against the hCA II isoform with an inhibition constant of $5.9 \mathrm{nM}$. This result indicated that compound 2a possessed 13-fold selectivity for hCA II over the hCA I isoform and 34- and 9-fold selectivity for hCA II over the hCA IX and XII isoforms, respectively. Similarly, compounds $\mathbf{2 b}, \mathbf{2 c}$, $\mathbf{2 d}, \mathbf{2 f}, \mathbf{2} \mathbf{h}$ and $\mathbf{2 0}$ exhibited potent and selective activity over the hCA II isoform with inhibition constant values of 7.3, 9.0,7.1, 16.0, 8.6 and 7.5 nM, respectively. On the contrary, the synthesized hybrids only displayed moderate inhibitory activity over the hCA IX isoform with inhibition constant ranging from 169.6-766.3 nM. All the synthesized hybrids displayed potent activity against the tumor-related hCA XII isoform with the most potent hybrids being compounds $2 \mathrm{c}$ and $\mathbf{2 n}$, which exhibited an inhibition constant of $36.9 \mathrm{nM}$. Except for compounds $\mathbf{2} \mathbf{f}$ and $\mathbf{2} \mathbf{h}$ which possessed moderate hCA XII inhibition constant of 257.0 and 235.6, respectively, the remaining synthesized hybrids displayed double-digit 
nanomolar activity ranging from $40.5-90.9 \mathrm{nM}$. The inhibitory activity of the synthesized hybrids over the hCA isoforms I, II, IX and XII is demonstrated in Table 2.

Table 2. Inhibition of hCA isoforms I, II, IX and XII by compounds 2a-0; acetazolamide (AAZ) was used as a standard inhibitor.

\begin{tabular}{|c|c|c|c|c|}
\hline \multirow{2}{*}{ Cpd } & \multicolumn{4}{|c|}{$K_{i}(n M)$} \\
\hline & hCA I & hCA II & hCA IX & hCA XII \\
\hline $2 a$ & 79.8 & 5.9 & 205.8 & 54.2 \\
\hline $2 b$ & 2796 & 7.3 & 286.5 & 85.1 \\
\hline $2 c$ & 217.3 & 9.0 & 221.6 & 36.9 \\
\hline $2 d$ & 97.6 & 7.1 & 165.5 & 42.2 \\
\hline $2 e$ & 5575 & 45.5 & 766.3 & 90.9 \\
\hline $2 f$ & 3105 & 16.0 & 165.1 & 257.0 \\
\hline $2 \mathrm{~g}$ & 4772 & 679.9 & 279.6 & 85.3 \\
\hline $2 \mathrm{~h}$ & 553.7 & 8.6 & 239.6 & 235.6 \\
\hline $2 \mathrm{i}$ & 7453 & 71.9 & 635.0 & 89.4 \\
\hline $2 j$ & 5397 & 94.8 & 654.0 & 40.5 \\
\hline $2 k$ & 4655 & 833.4 & 427.6 & 83.8 \\
\hline 21 & 4275 & 681.6 & 423.0 & 73.7 \\
\hline $2 \mathrm{~m}$ & 252.9 & 38.8 & 277.9 & 85.1 \\
\hline $2 n$ & 7511 & 670.1 & 487.3 & 36.9 \\
\hline 20 & 56.6 & 7.5 & 169.6 & 66.9 \\
\hline AAZ & 250.0 & 12.1 & 25.7 & 5.7 \\
\hline
\end{tabular}

Generally, the sulfonamides substituted at the para- and meta-positions generally exhibited higher inhibitory activity when compared to the ortho-substituted sulfonamideindole hybrids. Hydroxy substitutions in compounds $2 \mathrm{~g}$ and 21 led to a loss of the potent inhibitory activity. However, the hydroxy substituted compound $\mathbf{2} \mathbf{b}$ displayed a potent inhibitory activity on hCA II $\left(\mathrm{K}_{\mathrm{i}}=7.3 \mathrm{nM}\right)$ and XII $\left(\mathrm{K}_{\mathrm{i}}=85.1 \mathrm{nM}\right)$, which could be attributed to the presence of a longer amide linker. Similarly, in all the synthesized compounds, the longer amide linker usually led to higher activity when compared to a shorter one. Moreover, 3-substituted indoles (2a, 2b, $\mathbf{2} \mathbf{c}$ and $\mathbf{2 d}$ ) exhibited the highest activity when compared to 5 or 6-substituted indoles. Interestingly, the reverse amide 20 showed potent inhibitory activities against all hCA isoforms making it a potential lead for a new series of CA inhibitors. All the synthesized compounds showed potent activity against the tumorrelated hCA XII with inhibitory activity ranging from $36.9-257.0 \mathrm{nM}$. A structure activity relationship (SAR) diagram of the synthesized hybrids $\mathbf{2 a - 0}$ is illustrated in Figure 3.

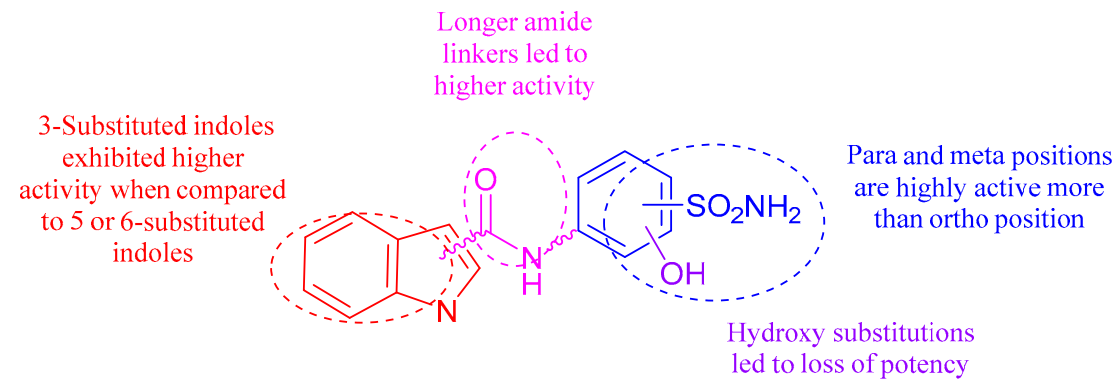

Figure 3. Structure activity relationship (SAR) diagram of the synthesized hybrids $\mathbf{2 a - 0}$.

\subsection{Molecular Docking Study}

The prediction of the binding modes between a ligand and its intended target, as well as the correlation of the obtained scores with prospective activity, are all different applications of molecular docking in computer-aided drug design research [23]. The ability to estimate the impact of specific amino acid mutations on the ligand's activity profile is another utility of molecular docking studies [24]. Additionally, visualizing the docking study's resulting interactions aids future ligand modification, resulting in molecules with 
better affinity properties [25]. Accordingly, a molecular docking study for synthesized hybrid compounds was performed for hCA isozymes I, II and IX to correlate the structural characteristics with the inhibitory activity and investigate the binding modes of the synthesized hybrids. Docking of the synthesized hybrids revealed that the benzenesulfonamide ring fits deeply inside the shallow CA active site, anchoring the zinc ion via a metal bond with $\mathrm{Zn}^{2+}$, which is typical for sulfonamide CAIs. Compound $\mathbf{2 a}$ was selected as a representative ligand to be docked over the different isoforms of CA due to its inhibitory profile, where it displayed a remarkable inhibitory profile over the tested isoforms with inhibition constant values of 79.8, 5.9, 205.8 and 54.2 nM over hCA I, II, IX and XII, respectively. For hCA I, compound $2 \mathbf{a}$ adhered to the common pattern of benzenesulfonamides, where the benzenesulfonamide ring fit deeply inside the surface CA active site through coordination with the zinc moiety in the distinctive manner of sulfonamide CAIs via $\mathrm{NH}^{-}-\mathrm{Zn}^{2+}$ bond (Figure 4A). Additionally, compound 2a established two hydrogen bonds between the oxygens of the sulfonamide moiety with THR199 and HIS200 amino acid residues, which stabilized the binding orientation of compound $\mathbf{2 a}$ inside the active site cavity (Figure 4B). The presence of the hydrogen bonds and metal coordination bonds, as well as the weak hydrophobic interactions, contributed to the potent inhibition profile exhibited by compound $\mathbf{2 a}$, as well as indicating a strong affinity to the active site of hCAI.

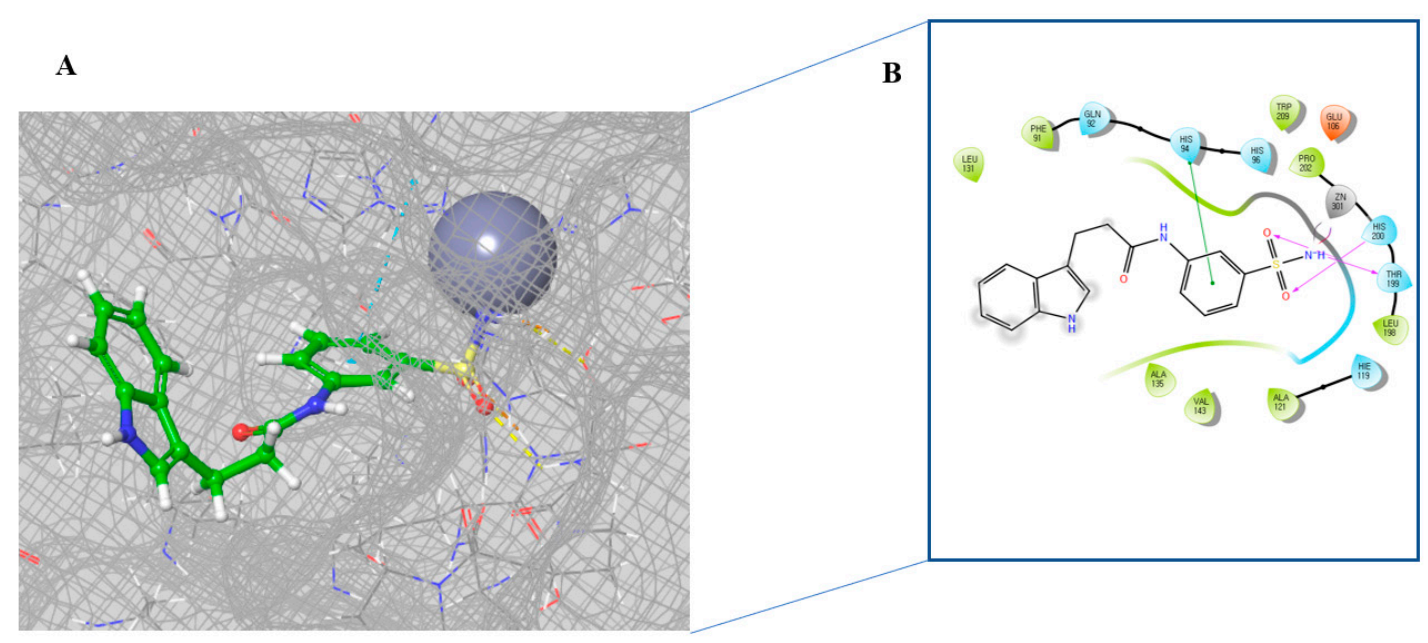

Figure 4. The interaction patterns of compound 2a in the active sites of hCAI. (A) 3D model of compound 2a surface CA active site, with the surface viewed in the mesh format. (B) 2D interaction pattern of compound 2a with hCA I active site.

Similarly, docking of compound $\mathbf{2 a}$ into the active site of hCA II exhibited the typical metal interaction of the sulfonamide group with the Zn metal (Figure 5B). Compound 2a established two additional hydrogen bonds with THR 199 amino acid residue of hCA II which increased the stability of the interaction. Furthermore, compound 2a occupied most of the available space of the shallow active site (Figure 5A) indicating a strong binding affinity between the compound and the active site residues. Docking of compound 2a into the active site of hCA IX (Figure 5C,D) established two metal interactions between the sulfonamide group and $\mathrm{Zn}^{2+}$ in the active site. It also exhibited a similar binding pattern when docked over the different isoforms of hCA, with the flexible amide linker allowing the ligand to fit deeply inside the active site surface to form the essential metal interaction with the $\mathrm{Zn}^{2+}$. 

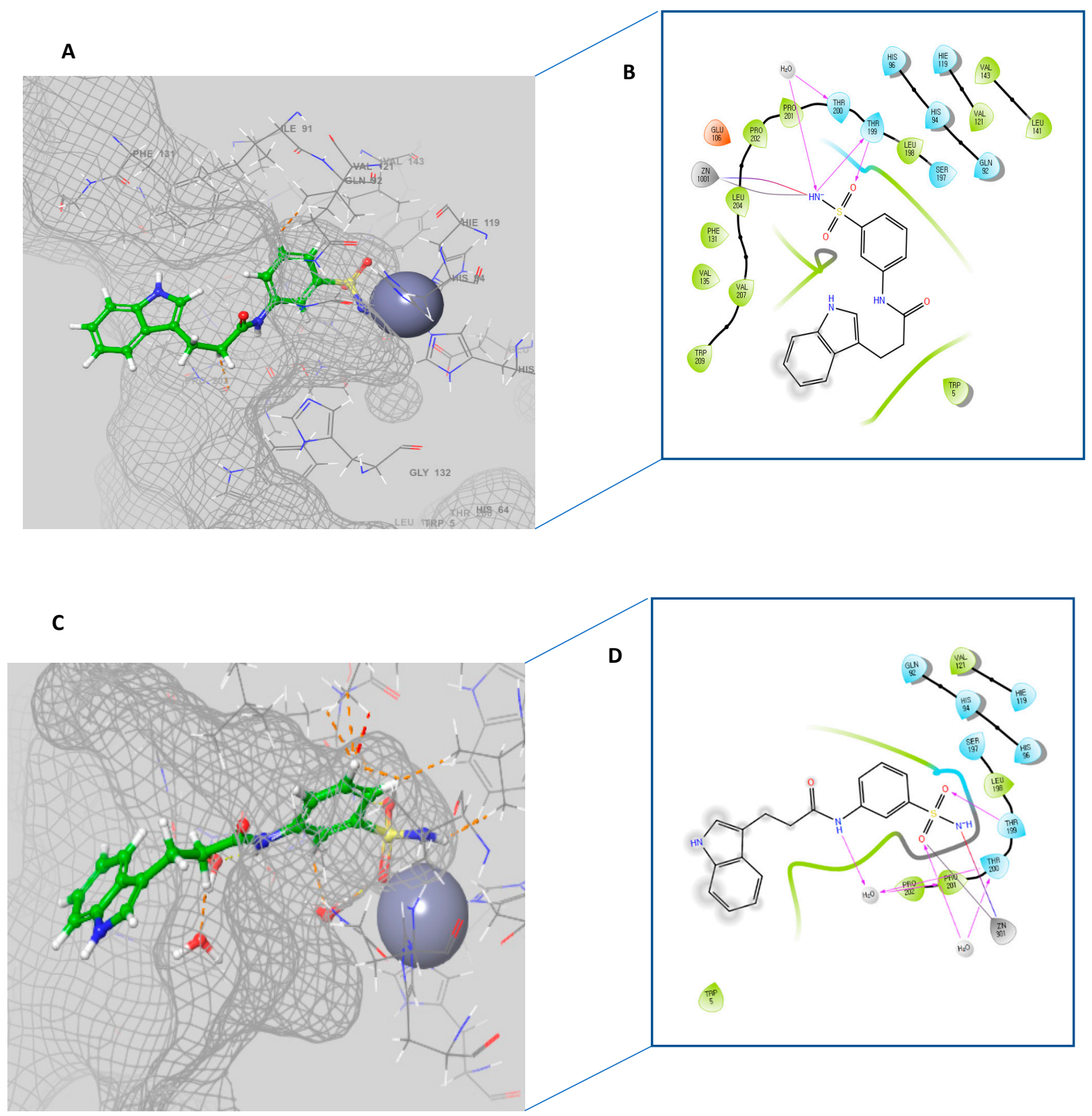

Figure 5. The interaction patterns of compound $\mathbf{2 a}$ in the active sites of hCA II and IX. (A) 3D model of compound 2a surface hCA II active site, with the surface viewed in the mesh format. (B) 2D interaction pattern of compound 2a with hCA II active site. (C) 3D model of compound 2a surface hCA IX active site, with the surface viewed in the mesh format. (D) 2D interaction pattern of compound $2 \mathrm{a}$ with hCA IX active site.

\section{Materials and Methods}

\subsection{Chemistry}

The commercial chemicals utilized herein were of reagent grade and were used without further purification. Thermo Scientific 9200 apparatus was employed to measure the melting point of the synthesized compounds. Proton nuclear magnetic resonance $\left({ }^{1} \mathrm{H}\right.$ NMR) spectra were established using a Varian $(400 \mathrm{MHz})$ spectrometer (Varian Medical Systems, Inc., Palo Alto, CA, USA). The ${ }^{1} \mathrm{H}$ NMR spectra multiplicity was shown as in the subsequent abbreviations: singlet (s), doublet (d), doublet of doublet (dd), triplet (t), quartet (q), multiplet (m), and broad (b). Chemical shift values are expressed in $\delta$ values (ppm), while the coupling 
constant $(J)$ values are reported in hertz. ${ }^{13} \mathrm{C}$ NMR spectra were obtained employing a Varian $(100 \mathrm{MHz})$ spectrometer and the chemical shifts values are reported in parts per million (ppm) downfield from tetramethylsilane (internal standard) with coupling constants in hertz, as previously reported [26,27]. The G2 QTOF mass spectrometer (Waters Corporation, Milford, MA, USA) was employed to produce the mass spectra, high-resolution mass spectrometry (HRMS, ESI-MS), as previously used [28]. Infrared (IR) spectra were documented as $\mathrm{KBr}$ disks utilizing a Shimadzu FT-IR $8400 S$ infrared spectrophotometer. The purification of the products was carried out employing column or flash column chromatography (Biotage, Uppsala, Sweden) with silica gel 60 (230-400 mesh Kieselgel 60), as previously carried out [29]. Moreover, monitoring of the reaction was achieved by employing thin-layer chromatography on $0.25 \mathrm{~mm}$ silica plates (E. Merck, silica gel 60 F254). High-performance liquid chromatography (HPLC) analysis was used to assess the optical purity of the synthesized compounds: Chiralpak IG-3 $(4.6 \times 150,3)$, hexane $/ \mathrm{EtOH} / \mathrm{MeOH}=85: 10: 5,1.5 \mathrm{~mL} / \mathrm{min}$, and $\lambda=280 \mathrm{~nm}$.

3-(1H-indol-3-yl)-N-(3-sulfamoylphenyl)propanamide (2a). In a round-bottom flask, the starting material 1a (3-(1H-indol-3-yl)propanoic acid, $0.10 \mathrm{~g}, 0.50 \mathrm{mmol})$, 1-ethyl-3-(3dimethylaminopropyl)carbodiimide (EDCI, $0.14 \mathrm{~g}, 0.75 \mathrm{mmol}$ ) and hydroxybenzotriazole (HOBt, $0.10 \mathrm{~g}, 0.75 \mathrm{mmol}$ ) were dissolved in $8 \mathrm{~mL}$ of acetonitrile (MeCN) and stirred at room temperature for $30 \mathrm{~min}$, followed by addition of the 3-aminobenzenesulfonamide $(0.09 \mathrm{~g}, 0.75 \mathrm{mmol})$. The reaction mixture was stirred at room temperature overnight. After completion of the reaction, excess solvent was evaporated. The obtained residue was diluted with EA, and the organic layer was washed with water and brine. The organic layer was then separated and dried over magnesium sulfate and filtered. The residue was purified by column chromatography on silica gel (0-20\% EA:Hex) to obtain the product. White solid. Yield: 35\%, mp: $202-204{ }^{\circ} \mathrm{C}$, HPLC purity: $9 \mathrm{~min}, 99.79 \%,{ }^{1} \mathrm{H}$ NMR $\left(400 \mathrm{MHz}, \mathrm{DMSO}-d_{6}\right)$ $\delta 10.78\left(\mathrm{~s}, 1 \mathrm{H}\right.$, indole-NH), $10.24\left(\mathrm{~s}, 1 \mathrm{H}\right.$, amide-NH), $8.18\left(\mathrm{~s}, 1 \mathrm{H}, \mathrm{Ph}-\mathrm{H} 2^{\prime}\right), 7.76-7.74(\mathrm{~m}$, $\left.1 \mathrm{H}, \mathrm{Ph}-\mathrm{H} 6^{\prime}\right), 7.58-7.56(\mathrm{~d}, J=8.00 \mathrm{~Hz}, 1 \mathrm{H}$, indolyl-H4), 7.49-7.47 (d, J = 8.00 Hz, 2H, Ph-H4 $4^{\prime}$ and $\left.5^{\prime}\right), 7.35\left(\mathrm{~s}, 2 \mathrm{H}, \mathrm{NH}_{2}\right), 7.34-7.32(\mathrm{~d}, 1 \mathrm{H}$, indolyl-H7), 7.13 (s, 1H, indolyl$\mathrm{H} 2), 7.08-7.04(\mathrm{t}, J=8.00 \mathrm{~Hz}, 1 \mathrm{H}$, indolyl-H6), 7.00-6.96 (t, $J=8.00 \mathrm{~Hz}, 1 \mathrm{H}$, indolyl-H5), 3.05-3.01 (t, $\left.J=8.00 \mathrm{~Hz}, 2 \mathrm{H}, \mathrm{CH}_{2}\right), 2.73-2.69\left(\mathrm{t}, J=8.00 \mathrm{~Hz}, 2 \mathrm{H}, \mathrm{CH}_{2}\right) .{ }^{13} \mathrm{C} \mathrm{NMR}(100 \mathrm{MHz}$, DMSO- $\left.d_{6}\right) \delta 171.81$ (C=O amide), 144.98 ( $\left.\mathrm{Ph}-\mathrm{C} 3^{\prime}\right), 140.03$ (Ph-C1'), 136.65 (indole-C7a), 129.84 (Ph-C5' $), 127.40$ (indole-C3a), 122.63 (indole-C2), 122.25 (Ph-C6 ${ }^{\prime}$ ), 121.38 (indole-C6), 120.49 (Ph-C4' $^{\prime}$, 118.78 (Ph-C2'), 118.62 (indole-C5), 116.42 (indole-C4), 113.95 (indole-C3), 111.78 (indole-C7), $37.70\left(\mathrm{CH}_{2}-\mathrm{C}=\mathrm{O}\right), 21.17$ (indole- $\left.\mathrm{CH}_{2}\right)$. HRMS (ESI) $\mathrm{m} / z$ calculated for $\mathrm{C}_{17} \mathrm{H}_{17} \mathrm{~N}_{3} \mathrm{O}_{3} \mathrm{~S}[\mathrm{M}+\mathrm{H}]^{+}: 344.1069$. Found: 344.1087 .

$N$-(2-hydroxy-5-sulfamoylphenyl)-3-(1H-indol-3-yl)propanamide (2b). In a dry roundbottom flask, compound $1 \mathrm{a}(0.20 \mathrm{~g}, 1.06 \mathrm{mmol})$, propylphosphonic anhydride (T3P, $1.20 \mathrm{~mL}$, $2.10 \mathrm{mmol})$ and DIPEA $(0.55 \mathrm{~mL}, 3.17 \mathrm{mmol})$ were dissolved in $8 \mathrm{~mL}$ of tetrahydrofuran (THF) and stirred at room temperature for $30 \mathrm{~min}$, followed by the addition of the 3-amino-4hydroxybenzenesulfonamide $(0.24 \mathrm{~g}, 1.27 \mathrm{mmol})$. The reaction mixture was stirred at room temperature overnight. After completion of the reaction, excess solvent was evaporated. The obtained residue was diluted with EA, and the organic layer was washed with water and brine. The organic layer was separated and dried over magnesium sulfate and filtered. The residue was purified by column chromatography on silica gel (0-5\% EA:Hex) to afford the product. Orange solid. Yield: $8.5 \%$, mp: $203-205^{\circ} \mathrm{C}, \mathrm{HPLC}$ purity: $8 \mathrm{~min}, 97.00 \%,{ }^{1} \mathrm{H}$ NMR $\left(400 \mathrm{MHz}, \mathrm{DMSO}-d_{6}\right) \delta 10.77$ (s, 1H, indole-NH), 9.37 (s, 1H, amide-NH), $8.42\left(\mathrm{~s}, 1 \mathrm{H}, \mathrm{Ph}-\mathrm{H}^{\prime}\right)$, 7.59-7.57 (d, J = 7.6 Hz, 1H, indolyl-H4), 7.41-7.38 (dd, J = 8.4, 2.3 Hz, 1H, Ph-H4'), 7.34-7.32 $\left(\mathrm{d}, J=7.8 \mathrm{~Hz}, 1 \mathrm{H}\right.$, indolyl-H7), $7.14\left(\mathrm{~s}, 1 \mathrm{H}\right.$, indolyl-H2), $7.13\left(\mathrm{~s}, 2 \mathrm{H}, \mathrm{NH}_{2}\right), 7.08-7.05(\mathrm{t}, 1 \mathrm{H}$, indolyl-H6), 7.00-6.94 (dd, $J=14.5,8.0 \mathrm{~Hz}, 2 \mathrm{H}, \mathrm{Ph}-\mathrm{H}^{\prime}$ and indolyl-H5), 3.04-2.98 (t, 2H, $\left.\mathrm{CH}_{2}\right)$, 2.87-2.74 (t, 2H, $\left.\mathrm{CH}_{2}\right) .{ }^{13} \mathrm{C}$ NMR (100 MHz, DMSO- $\left.d_{6}\right) \delta 174.25$ (amide-C=O), $153.10\left(\mathrm{Ph}^{-\mathrm{C} 2}{ }^{\prime}\right)$, 138.83 (Ph-C5'), 137.01 (indole-C7a), 129.63 (Ph-C1'), 128.92 (indole-C3a), 124.94 (Ph-C4'), 124.83 (indole-C2), 123.51 (indole-C6), 122.33 (Ph-C3'), 121.01 (indole-C5), 120.76 (indole-C4), $117.50\left(\mathrm{Ph}-\mathrm{C6}^{\prime}\right.$ ), 116.22 (indole-C3), 113.91 (indole-C7), $39.31\left(\mathrm{CH}_{2}-\mathrm{C}=\mathrm{O}\right), 23.46$ (indole- $\mathrm{CH}_{2}$ ). HRMS (ESI) $m / z$ calculated for $\mathrm{C}_{17} \mathrm{H}_{17} \mathrm{~N}_{3} \mathrm{O}_{4} \mathrm{~S}[\mathrm{M}+\mathrm{H}]^{+}:$360.1018. Found: 360.1010 . 
3-(1H-indol-3-yl)- $N$-(4-sulfamoylphenethyl)propanamide (2c). Following the synthetic procedure and work-up conditions of compound 2a, 4-(2-aminoethyl)benzenesulfonamide was reacted with the starting material 1a. The obtained residue was purified by column chromatography on silica gel (0-15\% EA:Hex). White solid. Yield: $25 \%$, mp: $236-237^{\circ} \mathrm{C}$, HPLC purity: $13 \mathrm{~min}, 99.00 \%,{ }^{1} \mathrm{H}$ NMR $\left(400 \mathrm{MHz}\right.$, DMSO- $\left.d_{6}\right) \delta 10.75$ (s, $1 \mathrm{H}$, indole-NH), $7.95\left(\mathrm{t}, 1 \mathrm{H}\right.$, amide-NH), $7.72-7.70\left(\mathrm{~d}, J=8.00 \mathrm{~Hz}, 2 \mathrm{H}, \mathrm{Ph}-\mathrm{H}^{\prime}{ }^{\prime}\right.$ and $\left.\mathrm{H}^{\prime}\right), 7.53-7.51(\mathrm{~d}, J=8.20 \mathrm{~Hz}$, $1 \mathrm{H}$, indolyl-H4)), $7.33\left(\mathrm{~s}, 2 \mathrm{H}, \mathrm{NH}_{2}\right), 7.31-7.29(\mathrm{~d}, J=8.20 \mathrm{~Hz}, 3 \mathrm{H}$, indoxyl-H7, and Ph-H2' and $\left.\mathrm{H6}^{\prime}\right), 7.08(\mathrm{~s}, 1 \mathrm{H}$, indolyl-H2), 7.06-7.04 (d, $J=8.20 \mathrm{~Hz}, 1 \mathrm{H}$, indolyl-H6)), 6.99-7.95 (t, $J=7.40 \mathrm{~Hz}, 1 \mathrm{H}$, indolyl-H5), 3.29-3.26 (q, $\left.J=6.50 \mathrm{~Hz}, 2 \mathrm{H}, \mathrm{CH}_{2}-\mathrm{NH}\right), 2.90-2.88(\mathrm{t}, J=7.4 \mathrm{~Hz}$, $\left.2 \mathrm{H}, \mathrm{CH}_{2}\right), 2.76-2.74\left(\mathrm{t}, J=7.00 \mathrm{~Hz}, 2 \mathrm{H}, \mathrm{CH}_{2}\right), 2.43-2.39\left(\mathrm{t}, J=7.60 \mathrm{~Hz}, 2 \mathrm{H}, \mathrm{CH}_{2}\right) .{ }^{13} \mathrm{C} \mathrm{NMR}$ $\left(100 \mathrm{MHz}, \mathrm{DMSO}-\mathrm{d}_{6}\right) \delta 172.30$ (amide-C=O), $144.40\left(\mathrm{Ph}^{-C} 1^{\prime}\right), 142.40$ (Ph-C4'), 136.64 (indole$\mathrm{C} 7 \mathrm{a}), 129.52$ (Ph-C3' and $\mathrm{C}^{\prime}$ ), 127.44 (indole-C3a), 126.06 ( $\mathrm{Ph}^{\prime} \mathrm{C}^{\prime}$ and $\left.\mathrm{C}^{\prime}\right), 122.53$ (indole-C2), 121.30 (indole-C6), 118.78 (indole-C5), 118.54 (indole-C4), 114.26 (indole-C3), 111.71 (indoleC7), $36.75\left(\mathrm{CH}_{2}-\mathrm{NH}\right), 35.28\left(\mathrm{CH}_{2}-\mathrm{C}=\mathrm{O}\right), 31.13\left(\mathrm{CH}_{2}-\mathrm{Ph}\right), 21.42$ (indole- $\left.\mathrm{CH}_{2}\right)$. HRMS (ESI) $\mathrm{m} / \mathrm{z}$ calculated for $\mathrm{C}_{19} \mathrm{H}_{21} \mathrm{~N}_{3} \mathrm{O}_{3} \mathrm{~S}[\mathrm{M}+\mathrm{H}]^{+}$: 372.1382. Found: 372.1371.

3-(1H-indol-3-yl)- $\mathrm{N}$-(4-sulfamoylphenyl)propanamide (2d). Following the synthetic procedure and work-up conditions of compound $\mathbf{2} \mathbf{b}$, 4 -aminobenzenesulfonamide was reacted with the starting material 1a. The obtained residue was purified by column chromatography on silica gel (0-25\% EA:Hex). White solid. Yield: 30\%, mp: 198-199 ${ }^{\circ} \mathrm{C}$, HPLC purity: $9 \mathrm{~min}, 99.98 \%,{ }^{1} \mathrm{H}$ NMR $\left(400 \mathrm{MHz}, \mathrm{DMSO}-d_{6}\right) \delta 10.78\left(\mathrm{~s}, 1 \mathrm{H}\right.$, indole-NH), $10.27\left(\mathrm{~s}, 1 \mathrm{H}\right.$, amide-NH), $7.75\left(\mathrm{~s}, 4 \mathrm{H}, \mathrm{Ph}-\mathrm{H} 2^{\prime}, 3^{\prime}\right.$, $5^{\prime}$, and $\left.6^{\prime}\right), 7.58-7.56(\mathrm{~d}, J=8.00 \mathrm{~Hz}, 1 \mathrm{H}$, indolyl-H4), 7.34-7.32 (d, $J=8.00 \mathrm{~Hz}, 1 \mathrm{H}$, indolyl-H7), $7.24\left(\mathrm{~s}, 2 \mathrm{H}, \mathrm{NH}_{2}\right), 7.13(\mathrm{~s}, 1 \mathrm{H}$, indolyl-H2), 7.08-7.05 (t, $J=8.00 \mathrm{~Hz}, 1 \mathrm{H}$, indolyl-H6), 7.00-6.96 (t, $J=8.00 \mathrm{~Hz}, 1 \mathrm{H}$, indolyl-H5), $3.05-3.01\left(\mathrm{t}, J=8.00 \mathrm{~Hz}, 2 \mathrm{H}, \mathrm{CH}_{2}\right), 2.71\left(\mathrm{t}, J=8.06 \mathrm{~Hz}, 2 \mathrm{H}, \mathrm{CH}_{2}\right)$. ${ }^{13} \mathrm{C}$ NMR (100 MHz, DMSO- $\left.d_{6}\right) \delta 171.98$ (amide-C=O), $142.60\left(\mathrm{Ph}-\mathrm{C} 1^{\prime}\right), 138.48$ (indole-C7a), 136.65 ( $\mathrm{Ph}-\mathrm{C}^{\prime}$ ), 127.40 (indole-C3a), 127.08 ( $\mathrm{Ph}-\mathrm{C}^{\prime}$ and $\mathrm{C}^{\prime}$ ), 122.63 (indole-C2), 121.37 (indole-C6), 118.93 (Ph-C2' and $\mathrm{C}^{\prime}$ ), 118.76 (indole-C5), 118.61 (indole-C4), 113.94 (indole-C7), 111.77 (indoleC3), $37.78\left(\mathrm{CH}_{2}-\mathrm{C}=\mathrm{O}\right), 20.94$ (indole- $\left.\mathrm{CH}_{2}\right)$. HRMS (ESI) $\mathrm{m} / z$ calculated for $\mathrm{C}_{17} \mathrm{H}_{17} \mathrm{~N}_{3} \mathrm{O}_{3} \mathrm{~S}[\mathrm{M}+\mathrm{H}]^{+}$: 344.1069. Found: 344.1065.

$\mathrm{N}$-(3-sulfamoylphenyl)-1H-indole-5-carboxamide (2e). Following the synthetic procedure and work-up conditions of compound $\mathbf{2 a}$, 3-aminobenzenesulfonamide was reacted with the starting material $\mathbf{1 b}$. The obtained residue was purified by column chromatography on silica gel (0-20\% EA:Hex) to obtain the product. White solid. Yield: $60 \%$, mp: $182-182{ }^{\circ} \mathrm{C}$, HPLC purity: $15 \mathrm{~min}, 96.78 \%,{ }^{1} \mathrm{H}$ NMR $\left(400 \mathrm{MHz}, \mathrm{DMSO}-d_{6}\right) \delta 11.83(\mathrm{~s}, 1 \mathrm{H}$, indole-NH), $8.66(\mathrm{~s}, 1 \mathrm{H}$, indolyl-H4), $8.20-8.18(\mathrm{~d}, J=8.70 \mathrm{~Hz}, 1 \mathrm{H}$, indolyl-H6), 7.98-7.96 (d, $\left.J=8.60 \mathrm{~Hz}, 1 \mathrm{H}, \mathrm{Ph}-\mathrm{H} 6^{\prime}\right), 7.00-7.88(\mathrm{~d}, J=8.30 \mathrm{~Hz}, 1 \mathrm{H}$, indolyl-H7), $7.69-7.67(\mathrm{~d}, J=8.60 \mathrm{~Hz}$, 2H, Ph-H4' and $\left.\mathrm{H}^{\prime}\right), 7.62\left(\mathrm{~s}, 1 \mathrm{H}, \mathrm{Ph}-\mathrm{H} 2^{\prime}\right), 7.57-7.53(\mathrm{t}, J=7.60 \mathrm{~Hz}, 1 \mathrm{H}$, indolyl-H2), $6.75(\mathrm{~s}$, $1 \mathrm{H}$, indolyl-H3). ${ }^{13} \mathrm{C}$ NMR (100 MHz, DMSO- $\left.d_{6}\right) \delta 164.22$ (amide-C=O), 143.26 (Ph-C3'), 140.24 (Ph-C1'), 129.65 (Ph-C5'), 128.99 (indole-C7a), 128.81 (indole-C5), 128.11 (Ph-C6'), 125.72 (indole-C3a), 125.45 (indole-C2), 123.26 ( $\left.\mathrm{Ph}-\mathrm{C} 4^{\prime}\right), 120.31$ (Ph-C2'), 114.36 (indole-C4), 112.86 (indole-C7), 109.76 (indole-C6), 103.73 (indole-C3). HRMS (ESI) $\mathrm{m} / \mathrm{z}$ calculated for $\mathrm{C}_{15} \mathrm{H}_{13} \mathrm{~N}_{3} \mathrm{O}_{3} \mathrm{~S}[\mathrm{M}+\mathrm{H}]^{+}:$316.0756. Found: 279.0872, 230.0630, 144.0434, 120.0550, and 111.0198 (see Supplementary Materials).

$\mathrm{N}$-(4-sulfamoylphenyl)-1H-indole-5-carboxamide (2f). Following the synthetic procedure and work-up conditions of compound 2a, 4-aminobenzenesulfonamide was reacted with the starting material $\mathbf{1 b}$. The obtained residue was diluted with EA and the organic layer was washed with water and brine. The obtained residue was purified by column chromatography on silica gel (0-20\% EA:Hex). White solid. Yield: $17 \%$, mp: $257-259^{\circ} \mathrm{C}$, HPLC purity: $15 \mathrm{~min}, 100 \%,{ }^{1} \mathrm{H}$ NMR $\left(400 \mathrm{MHz}, \mathrm{DMSO}-d_{6}\right) \delta 11.82(\mathrm{~s}, 1 \mathrm{H}$, indole-NH), $8.66(\mathrm{~s}, 1 \mathrm{H}$, indolyl-H4), 8.20-8.18 (d, $J=8.30 \mathrm{~Hz}, 1 \mathrm{H}$, indolyl-H6), 7.98-7.95 (d, J = 8.7 Hz, $1 \mathrm{H}$, indolyl-H7), 7.90-7.88 (d, $J=8.6 \mathrm{~Hz}, 1 \mathrm{H}$, indolyl-H2), 7.69-7.55 (m, 4H, $\mathrm{Ph}-\mathrm{H} 2^{\prime}, \mathrm{H}^{\prime}, \mathrm{H}^{\prime}$, and $\left.\mathrm{H}^{\prime}\right), 6.75$ (s, $1 \mathrm{H}$, indolyl-H3). ${ }^{13} \mathrm{C}$ NMR $\left(100 \mathrm{MHz}, \mathrm{DMSO}-\mathrm{d}_{6}\right) \delta 164.22$ (amide-C=O), 143.26 (Ph-C1'), 140.24 (Ph-C4'), 129.65 (Ph-C3' and 5'), 128.81 (indole-C7a), 128.11 (indoleC5), 125.45 (indole-C3a), 123.26 (indole-C2), 120.31 (Ph-C2' and 6'), 114.36 (indole-C4), 112.86 (indole-C7), 109.76 (indole-C6), 103.73 (indole-C3). HRMS (ESI) $\mathrm{m} / \mathrm{z}$ calculated for 
$\mathrm{C}_{15} \mathrm{H}_{13} \mathrm{~N}_{3} \mathrm{O}_{3} \mathrm{~S}[\mathrm{M}+\mathrm{H}]^{+}:$316.0756. Found: 279.0888, 144.0443, 120.0555, and 111.0207 (see Supplementary Materials).

$\mathrm{N}$-(2-hydroxy-5-sulfamoylphenyl)-1H-indole-5-carboxamide (2g). Following the synthetic procedure in dimethylformamide/dichloromethane $(\mathrm{DMF} / \mathrm{DCM}=5 / 1)$ and work-up conditions of compound 2a, 3-amino-4-hydroxybenzenesulfonamide was reacted with the starting material $\mathbf{~} \mathbf{b}$. The obtained residue was purified by column chromatography on silica gel (0-10\% EA:Hex). White solid. Yield: $0.63 \%$, mp: $189-190{ }^{\circ} \mathrm{C}$, HPLC purity: $15 \mathrm{~min}, 99.62 \%$, ${ }^{1} \mathrm{H}$ NMR $\left(400 \mathrm{MHz}\right.$, DMSO- $\left.d_{6}\right) \delta 11.82(\mathrm{~s}, 1 \mathrm{H}$, indole- $\mathrm{NH}), 8.66$ (s, $1 \mathrm{H}$, indolyl-H4), 8.20-8.18 (d, $J=8.60 \mathrm{~Hz}, 1 \mathrm{H}$, indolyl-H6), 7.98-7.95 (m, 1H, Ph-H4'), 7.90-7.88 (d, J = 8.30 Hz, $1 \mathrm{H}$, indolyl$\mathrm{H7}), 7.69-7.66\left(\mathrm{~m}, 2 \mathrm{H}, \mathrm{Ph}-\mathrm{H} 2^{\prime}\right.$ and $\left.\mathrm{H}^{\prime}\right), 7.63-7.61(\mathrm{~m}, 1 \mathrm{H}$, indolyl-H2), $6.75(\mathrm{~s}, 1 \mathrm{H}$, indolylH3). ${ }^{13} \mathrm{C}$ NMR (100 MHz, DMSO- $d_{6}$ ) $\delta 168.84$ (amide-C=O), 138.74 (indole-C7a), 128.22 (PhC5'), 127.76 (indole-C3a), 127.59 ( $\mathrm{Ph}-\mathrm{Cl}^{\prime}$ ), 127.34 (indole-C5), 124.93 (indole-C2), 123.22 (Ph$\left.\mathrm{C}^{\prime}\right), 122.62$ (Ph-C3'), 121.80 (indole-C4), 119.57 (Ph-C6'), 111.52 (indole-C7), 110.02 (indoleC6), 102.90 (indole-C3). HRMS (ESI) $\mathrm{m} / z$ calculated for $\mathrm{C}_{15} \mathrm{H}_{13} \mathrm{~N}_{3} \mathrm{O}_{4} \mathrm{~S}[\mathrm{M}+\mathrm{H}]^{+}: 332.0705$. Found: 332.0701 .

$\mathrm{N}$-(4-sulfamoylphenethyl)-1H-indole-5-carboxamide (2h). Following the synthetic procedure and work-up conditions of compound $\mathbf{2 b}, 4$-(2-aminoethyl)benzenesulfonamide was reacted with the starting material $\mathbf{1 b}$. The obtained residue was purified by column chromatography on silica gel (0-6\% DCM:MeOH). Orange solid. Yield: 35\%, mp: 209-211 ${ }^{\circ} \mathrm{C}$, HPLC purity: $6 \mathrm{~min}, 97.68 \%,{ }^{1} \mathrm{H}$ NMR $\left(400 \mathrm{MHz}, \mathrm{DMSO}-d_{6}\right) \delta 11.31(\mathrm{~s}, 1 \mathrm{H}$, indole- $\mathrm{NH}), 8.43-8.41(\mathrm{t}, 1 \mathrm{H}$, amide- $\mathrm{NH}), 8.08(\mathrm{~s}, 1 \mathrm{H}$, indolyl-H4), $7.75-7.73(\mathrm{~d}, J=8.00 \mathrm{~Hz}$, $2 \mathrm{H}, \mathrm{Ph}-\mathrm{H}^{\prime}$ and $\left.\mathrm{H}^{\prime}\right), 7.61-7.59(\mathrm{~d}, J=8.00 \mathrm{~Hz}, 1 \mathrm{H}$, indolyl-H6), 7.45-7.39 $(\mathrm{m}, 4 \mathrm{H}$, indolyl$\mathrm{H} 2$ and $\mathrm{H} 7 \& \mathrm{Ph}-\mathrm{H}^{\prime}{ }^{\prime}$ and $\left.\mathrm{H}^{\prime}\right), 7.28\left(\mathrm{~s}, 2 \mathrm{H}, \mathrm{NH}_{2}\right), 6.52(\mathrm{~s}, 1 \mathrm{H}$, indolyl-H3), 3.55-3.50 (m, $\left.2 \mathrm{H}, \mathrm{CH}_{2}\right), 2.96-2.92\left(\mathrm{t}, J=8.00 \mathrm{~Hz}, 2 \mathrm{H}, \mathrm{CH}_{2}-\mathrm{Ph}\right) .{ }^{13} \mathrm{C}$ NMR $\left(100 \mathrm{MHz}, \mathrm{DMSO}-d_{6}\right) \delta$ 167.71 (amide-C=O), $144.42\left(\mathrm{Ph}-\mathrm{C}^{\prime}{ }^{\prime}\right), 142.39\left(\mathrm{Ph}^{-C} 4^{\prime}\right), 137.75$ (indole-C7a), $129.56\left(\mathrm{Ph}-\mathrm{C}^{\prime}\right.$ and $\mathrm{C5}^{\prime}$ ), 127.38 (indole-C3a), 127.05 (indole-C5), 126.10 (Ph-C2' and $\mathrm{C}^{\prime}$ ), 125.95 (indole-C2), 120.86 (indole-C4), 120.17 (indole-C7), 111.26 (indole-C6), 102.47 (indole-C3), $35.40\left(\mathrm{CH}_{2}\right.$ $\mathrm{NH}), 31.12\left(\mathrm{CH}_{2}-\mathrm{Ph}\right)$. HRMS (ESI) $\mathrm{m} / z$ calculated for $\mathrm{C}_{17} \mathrm{H}_{17} \mathrm{~N}_{3} \mathrm{O}_{3} \mathrm{~S}[\mathrm{M}+\mathrm{H}]^{+} 344.1069$. Found: 344.1060 .

$\mathrm{N}$-(2-sulfamoylphenyl)- $\mathrm{H}$-indole-5-carboxamide (2i). Following the synthetic procedure and work-up conditions of compound $\mathbf{2 a}$, 2-aminobenzenesulfonamide was reacted with the starting material $\mathbf{1 b}$. The obtained residue was purified by column chromatography on silica gel (0-15\% EA:Hex). White solid. Yield: 23\%, mp: 192-193 ${ }^{\circ} \mathrm{C}$, HPLC purity: $15 \mathrm{~min}$, $98.02 \%,{ }^{1} \mathrm{H}$ NMR $\left(400 \mathrm{MHz}\right.$, DMSO- $\left.d_{6}\right) \delta 12.40(\mathrm{~s}, 1 \mathrm{H}$, amide-NH), $11.43(\mathrm{~s}, 1 \mathrm{H}$, indole-NH), $8.23(\mathrm{~s}, 1 \mathrm{H}$, indolyl-H4), 8.00-7.98 (d, $J=8.1 \mathrm{~Hz}, 1 \mathrm{H}$, indolyl-H6), 7.74-7.70 (t, $J=8.0 \mathrm{~Hz}, 2 \mathrm{H}, \mathrm{Ph}-$ $\mathrm{H} 4^{\prime}$ and $\left.\mathrm{H}^{\prime}\right)$, 7.57-7.53 (t, $1 \mathrm{H}$, indolyl-H2), 7.45-7.40 (m, 3H, indolyl-H7, and $\mathrm{Ph}-\mathrm{H} 3^{\prime}$ and $\mathrm{H}^{\prime}{ }^{\prime}$ ), 6.57 (s, 1H, indolyl-H3). ${ }^{13} \mathrm{C}$ NMR (100 MHz, DMSO- $d_{6}$ ) $\delta 164.21$ (amide-C=O), 143.26 (PhC2'), 140.24 (Ph-C1'), 129.63 (Ph-C5'), 128.99 (indole-C7a), 128.80 (indole-C5), 128.11 (Ph-C6'), 125.71 (indole-C3a), 125.44 (indole-C2), 123.25 ( $\left.\mathrm{Ph}-\mathrm{C} 4^{\prime}\right), 120.31$ (Ph-C2'), 114.36 (indole-C4), 112.85 (indole-C7), 109.75 (indole-C6), 103.72 (indole-C3).

$\mathrm{N}$-(3-sulfamoylphenyl)-1H-indole-6-carboxamide (2j). Following the synthetic procedure and work-up conditions of compound 2a, 3-aminobenzenesulfonamide was reacted with the starting material 1c. The obtained residue was recrystallized twice using methanol and DCM. Orange solid. Yield: 32\%, mp: 201-211 ${ }^{\circ} \mathrm{C}$, HPLC purity: $15 \mathrm{~min}, 99.67 \%,{ }^{1} \mathrm{H}$ NMR $\left(400 \mathrm{MHz}\right.$, DMSO- $\left.d_{6}\right) \delta 11.83(\mathrm{~s}, 1 \mathrm{H}$, indole-NH), $8.43(\mathrm{~s}, 1 \mathrm{H}$, indolyl-H7), $8.20-8.18(\mathrm{~d}, J=8.5 \mathrm{~Hz}$, $1 \mathrm{H}$, indolyl-H4), 7.92-7.80 (m, 4H, indolyl-H5, and Ph-H2' $\left.{ }^{\prime} \mathrm{H}^{\prime}, \mathrm{H6}^{\prime}\right), 7.70-7.66$ (m, 1H, Ph$\left.\mathrm{H}^{\prime}\right)$, 7.58-7.54 (m, $1 \mathrm{H}$, indolyl-H2), 6.69 (s, $1 \mathrm{H}$, indolyl-H3). ${ }^{13} \mathrm{C}$ NMR (100 MHz, DMSO- $\left.d_{6}\right)$ $\delta 164.24$ (amide-C=O), 143.26 ( $\left.\mathrm{Ph}-\mathrm{C} 3^{\prime}\right), 135.48$ (Ph-C1'), 133.75 (indole-C7a), 131.98 (Ph-C5'), 129.65 (Ph-C6'), 129.00 (indole-C3a), 125.73 (indole-C6), 121.25 (indole-C2), 120.74 (Ph-C4'), 120.31 (Ph-C2'), 115.76 (indole-C4), 115.73 (indole-C5), 109.79 (indole-C7), 102.72 (indole-C3).

$\mathrm{N}$-(4-sulfamoylphenyl)-1H-indole-6-carboxamide (2k). Following the synthetic procedure and work-up conditions of compound 2a, 4-aminobenzenesulfonamide was reacted with the starting material 1c. The obtained residue was purified by column chromatography on silica gel (0-20\% EA:Hex). White solid. Yield: $13 \%, \mathrm{mp}: 221-222{ }^{\circ} \mathrm{C}$, 
HPLC purity: $15 \mathrm{~min}, 99.90 \%,{ }^{1} \mathrm{H}$ NMR (400 MHz, DMSO-d 6 ) $\delta 11.83$ (s, 1H, indole-NH), 8.42 (s, 1H, indolyl-H7), 8.20-8.18 (d, $J=8.5 \mathrm{~Hz}, 1 \mathrm{H}$, indolyl-H4), 7.92-7.60 (m, 4H, Ph$\mathrm{H} 2^{\prime}, \mathrm{H}^{\prime}, \mathrm{H}^{\prime}$ and $\left.\mathrm{H6}^{\prime}\right), 7.70-7.66(\mathrm{t}, 1 \mathrm{H}$, indolyl-H5), 7.58-7.53 (t, 1H, indolyl-H2), 6.69 (s, $1 \mathrm{H}$, indolyl-H3). ${ }^{13} \mathrm{C}$ NMR (100 MHz, DMSO- $\left.d_{6}\right) \delta 168.80$ (amide-C=O), $135.58\left(\mathrm{Ph}-\mathrm{C}^{\prime}\right.$ ), 131.47 (Ph-C4'), 129.32 (indole-C4), 128.23 (indole-C7a), 127.80 (indole-C3a), 124.93 (indoleC6), 123.52 (indole-C2), 120.20 (Ph-C2' and $\mathrm{C}^{\prime}$ ), 120.01 (Ph-C3 ${ }^{\prime}$ and $\mathrm{C}^{\prime}$ ), 113.94 (indole-C5), 109.99 (indole-C7), 101.87 (indole-C3).

$\mathrm{N}$-(2-hydroxy-5-sulfamoylphenyl)- $1 H$-indole-6-carboxamide (21). Following the synthetic procedure and work-up conditions of compound 2a, 3-amino-4-hydroxybenzenesulfonamide was reacted with the starting material 1c. The obtained residue was purified by column chromatography on silica gel (0-15\% EA:Hex). Orange solid. Yield: $23 \%$, mp: $213-215{ }^{\circ} \mathrm{C}, \mathrm{HPLC}$ purity: $15 \mathrm{~min}, 98.03 \%,{ }^{1} \mathrm{H}$ NMR (400 MHz, DMSO- $\left.d_{6}\right) \delta 11.45$ (s, 1H, indole-NH), 8.05 (s, $1 \mathrm{H}$, indolyl-H7), 8.00-7.98 (d, $J=8.4 \mathrm{~Hz}, 1 \mathrm{H}$, indolyl-H4), 7.73-7.71 (d, J = 8.4 Hz, 1H, Ph$\left.\mathrm{H}^{\prime}\right), 7.60-7.53\left(\mathrm{~m}, 4 \mathrm{H}\right.$, indolyl-H5, $\mathrm{OH}$, and $\mathrm{Ph}-\mathrm{H} 4^{\prime}$ and $\left.\mathrm{H}^{\prime}\right), 7.44-7.40(\mathrm{t}, 1 \mathrm{H}$, indolyl-H2), 6.52 (s, $1 \mathrm{H}$, indolyl-H3). ${ }^{13} \mathrm{C}$ NMR $\left(100 \mathrm{MHz}, \mathrm{DMSO}-d_{6}\right) \delta 168.80$ (amide-C=O), 135.57 (indoleC7a), 131.46 (Ph-C5'), 129.33 (indole-C3a), 128.22 (Ph-C1'), $127.74\left(\mathrm{Ph}-\mathrm{C} 4^{\prime}\right), 124.93$ (indole-C2), 123.51 (indole-C6), 120.20 (indole-C4), 120.01 (Ph-C3'), 119.53 (Ph-C6'), 113.94 (indole-C5), 110.04 (indole-C7), 101.87 (indole-C3). HRMS (ESI) $m / z$ calculated for $\mathrm{C}_{15} \mathrm{H}_{13} \mathrm{~N}_{3} \mathrm{O}_{4} \mathrm{~S}[\mathrm{M}+\mathrm{H}]^{+}$, 332.0705. Found: 332.0704 .

$N$-(4-sulfamoylphenethyl)- $1 H$-indole-6-carboxamide $(2 \mathrm{~m})$. Following the synthetic procedure with solvent (DMF/DCM = 5/1) and work-up conditions of compound $2 \mathbf{a}, 4-(2-$ aminoethyl)benzenesulfonamide was reacted with the starting material 1c. The obtained residue was purified by column chromatography on silica gel (0-10\% EA:Hex). White solid. Yield: $28 \%$, mp: $250-252{ }^{\circ} \mathrm{C}$, HPLC purity: $1 \mathrm{~min}, 96.73 \%,{ }^{1} \mathrm{H}$ NMR $\left(400 \mathrm{MHz}, \mathrm{DMSO}-d_{6}\right) \delta$ $11.37(\mathrm{~s}, 1 \mathrm{H}$, indole- $\mathrm{NH}), 8.49-8.46(\mathrm{t}, J=8.00 \mathrm{~Hz}, 1 \mathrm{H}$, amide- $\mathrm{NH}), 7.92(\mathrm{~s}, 1 \mathrm{H}$, indolyl-H7), 7.76-7.74 $\left(\mathrm{d}, J=8.00 \mathrm{~Hz}, 2 \mathrm{H}, \mathrm{Ph}-\mathrm{H3}^{\prime}\right.$ and $\left.\mathrm{H}^{\prime}\right), 7.57-7.55(\mathrm{~d}, J=8.00 \mathrm{~Hz}, 1 \mathrm{H}$, indolyl-H5), 7.50-7.48 (m, 2H, indolyl-H2 and H4), 7.45-7.43 (d, J = 8.00 Hz, 2H, Ph-H2' and H6'), 7.28 (s, $2 \mathrm{H}, \mathrm{NH}_{2}$ ), 6.47(s, 1H, indolyl-H3), 3.55-3.50 (q, 2H, $\left.\mathrm{CH}_{2}-\mathrm{NH}\right), 2.95-2.93(\mathrm{t}, J=8.00 \mathrm{~Hz}, 2 \mathrm{H}$, $\left.\mathrm{CH}_{2}-\mathrm{Ph}\right) .{ }^{13} \mathrm{C}$ NMR $\left(100 \mathrm{MHz}, \mathrm{DMSO}-d_{6}\right) \delta 167.63$ (amide-C=O), $144.40\left(\mathrm{Ph}-\mathrm{Cl}^{\prime}\right), 142.43(\mathrm{Ph}-$ $\mathrm{C4}^{\prime}$ ), 135.65 (indole-C7a), 130.17 (indole-C3a), 129.55 (Ph-C3' and $\mathrm{C}^{\prime}$ ), 128.31 (indoleC2), 127.82 (indole-C6), 126.11 (Ph-C2' and $\mathrm{C}^{\prime}$ ), 119.78 (indole-C4), 118.31 (indole-C5), 111.52 (indole-C7), 101.61 (indole-C3), $40.92\left(\mathrm{CH}_{2}-\mathrm{NH}\right), 35.38\left(\mathrm{CH}_{2}-\mathrm{Ph}\right)$.

$\mathrm{N}$-(2-sulfamoylphenyl)-1H-indole-6-carboxamide (2n). Following the synthetic procedure and work-up conditions of compound 2a, 2-aminobenzenesulfonamide was reacted with the starting material 1c. The obtained residue was purified by column chromatography on silica gel (0-12\% EA:Hex). White solid. Yield: 10\%, mp: $222-223{ }^{\circ} \mathrm{C}$, HPLC purity: $15 \mathrm{~min}$, $98.70 \%,{ }^{1} \mathrm{H}$ NMR (400 MHz, DMSO- $\left.d_{6}\right) \delta 11.82$ (s, 1H, indole-NH), 8.42 (s, 1H, indolyl-H7), 8.20-8.18 (d, J = 8.4 Hz, 1H, indolyl-H4), 7.91-7.89 (d, 2H, Ph-H3' and H6' $), 7.81-7.78(\mathrm{t}, 1 \mathrm{H}$, Ph-H4' $), 7.70-7.66\left(\mathrm{t}, J=7.3 \mathrm{~Hz}, 1 \mathrm{H}, \mathrm{Ph}-\mathrm{H}^{\prime}\right), 7.57-7.54(\mathrm{t}, 1 \mathrm{H}$, indolyl-H2), $6.69(\mathrm{~s}, 1 \mathrm{H}$, indolylH3). ${ }^{13} \mathrm{C}$ NMR (100 MHz, DMSO- $\left.d_{6}\right) \delta 164.24$ (amide-C=O), $143.26\left(\mathrm{Ph}-\mathrm{C} 2^{\prime}\right), 135.48\left(\mathrm{Ph}-\mathrm{C1}^{\prime}\right)$, 133.74 (indole-C7a), 129.66 (Ph-C3'), 128.99 (indole-C3a), 125.74 (indole-C6), 121.25 (indoleC2), 120.74 (Ph-C5'), 120.32 (Ph-C4'), 120.20 (Ph-C6' $)$, 115.75 (indole-C4), 115.72 (indole-C5), 109.80 (indole-C7), 102.72 (indole-C3).

$\mathrm{N}$-(1H-indol-5-yl)-4-sulfamoylbenzamide (2o). Following the synthetic procedure with solvent (DMF/DCM = 5/1) and work-up conditions of compound $\mathbf{2 a}$, 4-sulfamoylbenzoic acid was reacted with the starting material $1 \mathrm{~d}$. The obtained residue was purified by column chromatography on silica gel (0-8\% DCM:MeOH). Purple solid. Yield: 25\%, mp: 261-262 ${ }^{\circ} \mathrm{C}$, HPLC purity: $6 \mathrm{~min}, 97.38 \%,{ }^{1} \mathrm{H}$ NMR (400 MHz, DMSO- $\left.d_{6}\right) \delta 11.06$ (s, $1 \mathrm{H}$, indole-NH), $10.26\left(\mathrm{~s}, 1 \mathrm{H}\right.$, amide-NH), $8.13-8.11\left(\mathrm{~d}, J=8.00 \mathrm{~Hz}, 2 \mathrm{H}, \mathrm{Ph}-\mathrm{H} 2^{\prime}\right.$ and $\left.\mathrm{H} 6^{\prime}\right), 8.00\left(\mathrm{~s}, 1 \mathrm{H}\right.$, indolyl-H4 $\left.{ }^{\prime}\right)$, 7.96-7.94 (d, J = 8.00 Hz, 2H, Ph-H3 ${ }^{\prime}$ and H5'), $7.52\left(\mathrm{~s}, 2 \mathrm{H}, \mathrm{NH}_{2}\right), 7.41-7.33(\mathrm{~m}, 3 \mathrm{H}$, indolyl-H2, H6, and H7), 6.42 (s, 1H, indolyl-H3). ${ }^{13} \mathrm{C} \mathrm{NMR}\left(100 \mathrm{MHz}, \mathrm{DMSO}-d_{6}\right) \delta 164.44$ (amide-C=O), 146.61 (Ph-C4'), 138.79 (Ph-C1'), 133.52 (indole-C7a), 131.07 (indole-C5), 128.64 (Ph-C2' and $\mathrm{C6}^{\prime}$ ), 127.81 (indole-C2), 126.43 (indole-C3a), 126.03 (Ph-C3' and C5'), 116.38 (indole-C6), 
112.64 (indole-C7), 111.53 (indole-C4), 101.63 (indole-C3). HRMS (ESI) $\mathrm{m} / \mathrm{z}$ calculated for $\mathrm{C}_{15} \mathrm{H}_{13} \mathrm{~N}_{3} \mathrm{O}_{3} \mathrm{~S}[\mathrm{M}+\mathrm{H}]^{+}$316.0756. Found: 316.0757.

\subsection{Carbonic Anhydrase Inhibition}

The inhibitor and enzyme solutions were first preincubated together for $15 \mathrm{~min}$ at room temperature to enable for the generation of the E-I complex. Photophysics stoppedflow instrument was used to measure the $\mathrm{CA}$-catalyzed $\mathrm{CO}_{2}$ hydration activity. Phenol red (at a concentration of $0.2 \mathrm{mM}$ ) was added as an indicator after a period of 10-100 s in the CA-catalyzed $\mathrm{CO}_{2}$ hydration reaction at an absorbance maximum of $557 \mathrm{~nm}$, with $20 \mathrm{mM}$ Hepes ( $\mathrm{pH}=7.4)$ and $10 \mathrm{mM} \mathrm{NaClO}_{4}$ (to maintain constant ionic strength) [30]. The kinetic parameters and inhibition constants were calculated at $\mathrm{CO}_{2}$ concentrations ranging from 1.7 to $17 \mathrm{mM}$ [31]. In the initial $5-10 \%$ of the reaction, at least six traces were examined to determine the initial velocity for each inhibitor. Similarly, the total measured rates were used to measure the uncatalyzed rates [32]. Distilled-deionized water was used in the preparation of the Stock inhibitor solutions $(10 \mathrm{mM})$, as well as dilutions up to $0.01 \mathrm{nM}$. The inhibition constants were measured utilizing PRISM 3, whereas the Lineweaver-Burk plots were used to measure the kinetic parameters which comprised the mean of at least three separate measurements $[33,34]$.

\subsection{Molecular Docking}

hCA I (PDB code: 6Y00, resolution $1.37 \AA$ ) [35], hCA II (PDB code: 4BF1, resolution $1.35 \AA$ ) and hCA IX (PDB code: 4ZWX, resolution $1.70 \AA$ ) [36] crystal structures were retrieved from the Protein Data Bank (www.pdb.org, accessed on 19 February 2022). The downloaded crystal structures were prepared employing the preparation wizard of the Schrodinger 2021 suite package under the default settings with the $\mathrm{pH}$ value set at a value of 7.4. All ligands were first sketched via ChemDraw Professional 17.0, then exported as a structure data file format and sent to the Ligprep module. Ligand preparation was achieved utilizing the Schrodinger Ligprep module to optimize the geometry of the studied ligands. Glide's standard precision module was employed to dock the minimized ligands into the appropriate crystal structure binding site, yielding 10 poses for each docked ligand.

\section{Conclusions}

A new hybrid series of indole-based benzenesulfonamides were successfully synthesized, characterized, and biologically evaluated against four isoforms of CA (I, II, IX, and XII). The inhibitory activities of the hybrid compounds $\mathbf{2 a - 0}$ and AAZ, as a standard inhibitor, were measured against the four isoforms of hCA by a stopped flow $\mathrm{CO}_{2}$ hydrase assay. Compared to $\mathrm{AAZ}$, compounds $\mathbf{2 a}, \mathbf{2} \mathbf{d}$ and $\mathbf{2 o}$ showed higher inhibitory activities over hCA I. Among all, compound 2a displayed the most potent activity and selectivity against hCA II. Compounds $\mathbf{2 b}, \mathbf{2 c}, \mathbf{2 d}, \mathbf{2 f}, \mathbf{2} \mathbf{h}$ and $\mathbf{2 o}$ also showed low nanomolar inhibitory activities against hCA II. The selectivity profiles of the synthesized target compounds, as well as their SAR, display the high potential of this series to be further investigated as a promising lead towards more potent and selective hCA II inhibitors.

Supplementary Materials: The following supporting information can be downloaded at: https:/ /www. mdpi.com/article/10.3390/ijms23052540/s1. NMR, HPLC, and HRMS representative data for the newly synthesized compounds in this article.

Author Contributions: Conceptualization, A.E. and K.L.; resources, K.L.; project administration, A.E.; synthesis and data analysis, A.E., J.W. and T.M.B.; determination of inhibitory activity against hCA, A.A. and C.T.S.; molecular docking and modeling, H.N.; Structure-activity relationship determination, A.E. and H.N.; writing-original draft preparation, A.E., J.W., H.N., T.M.B.; writing-review and editing, all authors. All authors have read and agreed to the published version of the manuscript.

Funding: This research was supported by National Research Foundation of Korea (NRF) grant funded by the Korea government (MSIT) (No. 2018R1A5A2023127) and the BK21 FOUR program through NRF funded by the Ministry of Education of Korea. 


\section{Institutional Review Board Statement: Not applicable.}

Informed Consent Statement: Not applicable.

Data Availability Statement: Data are contained within the article.

Acknowledgments: A.E. extends his appreciation to Korea Institute of Science and Technology (KIST) for supporting this work through "2022 KIST School Partnership project" and in the accomplishment of this project, he would like to thank the Technology Innovation Commercial Office (TICO) at Mansoura University for their highly effective contribution.

Conflicts of Interest: The authors declare no conflict of interest.

\section{References}

1. Nocentini, A.; Supuran, C.T.; Capasso, C. An overview on the recently discovered iota-carbonic anhydrases. J. Enzym. Inhib. Med. Chem. 2021, 36, 1988-1995. [CrossRef] [PubMed]

2. Supuran, C.T. Carbonic anhydrases: Novel therapeutic applications for inhibitors and activators. Nat. Rev. Drug Discov. 2008, 7, 168-181. [CrossRef] [PubMed]

3. Topal, F.; Aksu, K.; Gulcin, I.; Tümer, F.; Goksu, S. Inhibition Profiles of Some Symmetric Sulfamides Derived from Phenethylamines on Human Carbonic Anhydrase, I.; and II Isoenzymes. Chem. Biodivers. 2021, 18, e2100422. [CrossRef] [PubMed]

4. Durdagi, S.; Şentürk, M.; Ekinci, D.; Balaydın, H.T.; Göksu, S.; Küfrevioğlu, Ö.İ.; Innocenti, A.; Scozzafava, A.; Supuran, C.T. Kinetic and docking studies of phenol-based inhibitors of carbonic anhydrase isoforms I, II, IX and XII evidence a new binding mode within the enzyme active site. Bioorg. Med. Chem. 2011, 19, 1381-1389. [CrossRef] [PubMed]

5. Supuran, C.T.; Scozzafava, A. Carbonic anhydrase inhibitors and their therapeutic potential. Expert Opin. Ther. Pat. 2000, 10, 575-600. [CrossRef]

6. Mohamed, M.M.; Sloane, B.F. multifunctional enzymes in cancer. Nat. Rev. Cancer 2006, 6, 764-775. [CrossRef]

7. Haapasalo, J.; Nordfors, K.; Järvelä, S.; Bragge, H.; Rantala, I.; Parkkila, A.-K.; Haapasalo, H.; Parkkila, S. Carbonic anhydrase II in the endothelium of glial tumors: A potential target for therapy. Neuro-Oncol. 2007, 9, 308-313. [CrossRef]

8. Cuffaro, D.; Nuti, E.; Rossello, A. An overview of carbohydrate-based carbonic anhydrase inhibitors. J. Enzym. Inhib. Med. Chem. 2020, 35, 1906-1922. [CrossRef]

9. Awadallah, F.M.; Bua, S.; Mahmoud, W.R.; Nada, H.H.; Nocentini, A.; Supuran, C.T. Inhibition studies on a panel of human carbonic anhydrases with N1-substituted secondary sulfonamides incorporating thiazolinone or imidazolone-indole tails. $J$. Enzym. Inhib. Med. Chem. 2018, 33, 629-638. [CrossRef]

10. Supuran, C.T. Carbon- versus sulphur-based zinc binding groups for carbonic anhydrase inhibitors? J. Enzym. Inhib. Med. Chem. 2018, 33, 485-495. [CrossRef]

11. Sanku, R.K.K. Development and Biological Evaluation of Carbonic Anhydrase Modulators as Potential Nootropics and Anticancer Agents. Ph.D. Thesis, Temple University, Ann Arbor, MI, USA, 2018.

12. Supuran, C.T. Advances in structure-based drug discovery of carbonic anhydrase inhibitors. Expert Opin. Drug Discov. 2017, 12, 61-88. [CrossRef] [PubMed]

13. Supuran, C.T. Exploring the multiple binding modes of inhibitors to carbonic anhydrases for novel drug discovery. Expert Opin. Drug Discov. 2020, 15, 671-686. [CrossRef] [PubMed]

14. Aggarwal, M.; Kondeti, B.; McKenna, R. Insights towards sulfonamide drug specificity in $\alpha$-carbonic anhydrases. Bioorg. Med. Chem. 2013, 21, 1526-1533. [CrossRef] [PubMed]

15. Carta, F.; Supuran, C.T.; Scozzafava, A. Sulfonamides and their isosters as carbonic anhydrase inhibitors. Future Med. Chem. 2014, 6, 1149-1165. [CrossRef] [PubMed]

16. Chiaramonte, N.; Bua, S.; Ferraroni, M.; Nocentini, A.; Bonardi, A.; Bartolucci, G.; Durante, M.; Lucarini, L.; Chiapponi, D.; Dei, S.; et al. 2-Benzylpiperazine: A new scaffold for potent human carbonic anhydrase inhibitors. Synthesis, enzyme inhibition, enantioselectivity, computational and crystallographic studies and in vivo activity for a new class of intraocular pressure lowering agents. Eur. J. Med. Chem. 2018, 151, 363-375. [CrossRef] [PubMed]

17. Singh, P.; Swain, B.; Thacker, P.S.; Sigalapalli, D.K.; Yadav, P.P.; Angeli, A.; Supuran, C.T.; Arifuddin, M. Synthesis and carbonic anhydrase inhibition studies of sulfonamide based indole-1,2,3-triazole chalcone hybrids. Bioorg. Chem. 2020, 99 , 103839. [CrossRef] [PubMed]

18. Demir-Yazıc1, K.; Bua, S.; Akgüneş, N.M.; Akdemir, A.; Supuran, C.T.; Güzel-Akdemir, Ö. Indole-Based Hydrazones Containing A Sulfonamide Moiety as Selective Inhibitors of Tumor-Associated Human Carbonic Anhydrase Isoforms IX and XII. Int. J. Mol. Sci. 2019, 20, 2354. [CrossRef]

19. Peerzada, M.N.; Khan, P.; Ahmad, K.; Hassan, M.I.; Azam, A. Synthesis, characterization and biological evaluation of tertiary sulfonamide derivatives of pyridyl-indole based heteroaryl chalcone as potential carbonic anhydrase IX inhibitors and anticancer agents. Eur. J. Med. Chem. 2018, 155, 13-23. [CrossRef]

20. George, R.F.; Bua, S.; Supuran, C.T.; Awadallah, F.M. Synthesis of some N-aroyl-2-oxindole benzenesulfonamide conjugates with carbonic anhydrase inhibitory activity. Bioorg. Chem. 2020, 96, 103635. [CrossRef] 
21. Assi, R.; Kantarjian, H.M.; Kadia, T.M.; Pemmaraju, N.; Jabbour, E.; Jain, N.; Daver, N.; Estrov, Z.; Uehara, T.; Owa, T.; et al. Final results of a phase 2, open-label study of indisulam, idarubicin, and cytarabine in patients with relapsed or refractory acute myeloid leukemia and high-risk myelodysplastic syndrome. Cancer 2018, 124, 2758-2765. [CrossRef]

22. Bozdag, M.; Carta, F.; Ceruso, M.; Ferraroni, M.; McDonald, P.C.; Dedhar, S.; Supuran, C.T. Discovery of 4-Hydroxy-3-(3(phenylureido)benzenesulfonamides as SLC-0111 Analogues for the Treatment of Hypoxic Tumors Overexpressing Carbonic Anhydrase IX. J. Med. Chem. 2018, 61, 6328-6338. [CrossRef] [PubMed]

23. Macalino, S.J.Y.; Gosu, V.; Hong, S.; Choi, S. Role of computer-aided drug design in modern drug discovery. Arch. Pharmacal Res. 2015, 38, 1686-1701. [CrossRef] [PubMed]

24. Guedes, I.A.; de Magalhães, C.S.; Dardenne, L.E.J.B.R. Receptor-ligand molecular docking. Biophys. Rev. 2014, 6, 75-87. [CrossRef] [PubMed]

25. Wang, J.; Li, Y.; Yang, Y.; Du, J.; Zhang, S.; Yang, L. In silico research to assist the investigation of carboxamide derivatives as potent TRPV1 antagonists. Mol. Biosyst. 2015, 11, 2885-2899. [CrossRef] [PubMed]

26. Elkamhawy, A.; Kim, N.Y.; Hassan, A.H.E.; Park, J.E.; Yang, J.E.; Oh, K.S.; Lee, B.H.; Lee, M.Y.; Shin, K.J.; Lee, K.T.; et al. Design, synthesis and biological evaluation of novel thiazolidinedione derivatives as irreversible allosteric IKK- $\beta$ modulators. Eur. J. Med. Chem. 2018, 157, 691-704. [CrossRef]

27. Park, J.E.; Elkamhawy, A.; Hassan, A.H.E.; Pae, A.N.; Lee, J.; Paik, S.; Park, B.G.; Roh, E.J. Synthesis and evaluation of new pyridyl/pyrazinyl thiourea derivatives: Neuroprotection against amyloid- $\beta$-induced toxicity. Eur. J. Med. Chem. 2017, 141, 322-334. [CrossRef]

28. Elkamhawy, A.; Hassan, A.H.E.; Paik, S.; Sup Lee, Y.; Lee, H.H.; Shin, J.S.; Lee, K.T.; Roh, E.J. EGFR inhibitors from cancer to inflammation: Discovery of 4-fluoro- $N$-(4-(3-(trifluoromethyl)phenoxy)pyrimidin-5-yl)benzamide as a novel anti-inflammatory EGFR inhibitor. Bioorg. Chem. 2019, 86, 112-118. [CrossRef]

29. Al-Sanea, M.M.; Elkamhawy, A.; Zakaria, A.; Park, B.S.; Kwon, Y.; Lee, S.H.; Lee, S.W.; Kim, I.T. Synthesis and in vitro screening of phenylbipyridinylpyrazole derivatives as potential antiproliferative agents. Molecules 2015, 20, 1031-1045. [CrossRef]

30. Maresca, A.; Temperini, C.; Vu, H.; Pham, N.B.; Poulsen, S.-A.; Scozzafava, A.; Quinn, R.J.; Supuran, C.T. Non-Zinc Mediated Inhibition of Carbonic Anhydrases: Coumarins Are a New Class of Suicide Inhibitors. J. Am. Chem. Soc. 2009, 131, 3057-3062. [CrossRef]

31. Alafeefy, A.M.; Ceruso, M.; Al-Jaber, N.A.; Parkkila, S.; Vermelho, A.B.; Supuran, C.T. A new class of quinazoline-sulfonamides acting as efficient inhibitors against the $\alpha$-carbonic anhydrase from Trypanosoma cruzi. J. Enzym. Inhib. Med. Chem. 2015, 30, 581-585. [CrossRef]

32. Menchise, V.; De Simone, G.; Alterio, V.; Di Fiore, A.; Pedone, C.; Scozzafava, A.; Supuran, C.T. Carbonic Anhydrase Inhibitors: Stacking with Phe131 Determines Active Site Binding Region of Inhibitors As Exemplified by the X-ray Crystal Structure of a Membrane-Impermeant Antitumor Sulfonamide Complexed with Isozyme II. J. Med. Chem. 2005, 48, 5721-5727. [CrossRef]

33. Margheri, F.; Ceruso, M.; Carta, F.; Laurenzana, A.; Maggi, L.; Lazzeri, S.; Simonini, G.; Annunziato, F.; Del Rosso, M.; Supuran, C.T.; et al. Overexpression of the transmembrane carbonic anhydrase isoforms IX and XII in the inflamed synovium. J. Enzym. Inhib. Med. Chem. 2016, 31, 60-63. [CrossRef] [PubMed]

34. Bozdag, M.; Ferraroni, M.; Nuti, E.; Vullo, D.; Rossello, A.; Carta, F.; Scozzafava, A.; Supuran, C.T. Combining the tail and the ring approaches for obtaining potent and isoform-selective carbonic anhydrase inhibitors: Solution and X-ray crystallographic studies. Bioorg, Med. Chem. 2014, 22, 334-340. [CrossRef] [PubMed]

35. Ali, M.; Bozdag, M.; Farooq, U.; Angeli, A.; Carta, F.; Berto, P.; Zanotti, G.; Supuran, C.T. Benzylaminoethyureido-Tailed Benzenesulfonamides: Design, Synthesis, Kinetic and X-ray Investigations on Human Carbonic Anhydrases. Int. J. Mol. Sci. 2020, 21, 2560. [CrossRef] [PubMed]

36. Mahon, B.P.; Lomelino, C.L.; Ladwig, J.; Rankin, G.M.; Driscoll, J.M.; Salguero, A.L.; Pinard, M.A.; Vullo, D.; Supuran, C.T.; Poulsen, S.-A.; et al. Mapping Selective Inhibition of the Cancer-Related Carbonic Anhydrase IX Using Structure-Activity Relationships of Glucosyl-Based Sulfamates. J. Med. Chem. 2015, 58, 6630-6638. [CrossRef] [PubMed] 